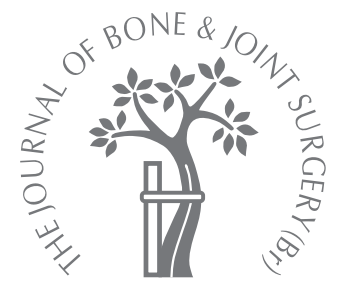

G. A. Macheras, P. J. Papagelopoulos, K. Kateros,

A. T. Kostakos,

D. Baltas,

T. S. Karachalios

From the First IKA

Hospital, Athens,

Greece

G. A. Macheras, MD,

Consultant and Director

A. T. Kostakos, MD,

Consultant

D. Baltas, MD, Consultant Department of Orthopaedics First IKA Hospital Athens, 1

Zaimi Street, 15127, Athens,

Greece.

P. J. Papagelopoulos, MD, DSc, Assistant Professor and Consultant

First Department of

Orthopaedics

Athens University Medical

School, 4 Christovassili

Street, Neo Psychikon, 15451

Athens, Greece.

K. Kateros, MD, Consultant Department of Orthopaedics General Hospital of Levadia 106 Kafkassou, 11363 Athens, Greece.

T. S. Karachalios, MD, Associate Professor and Consultant

Orthopaedic Department

School of Medicine, Faculty

of Health Sciences,

University of Thessaly, 22

Papakyriazi Street, Larissa

41222, Greece.

Correspondence should be sent to $\mathrm{Dr}$ G. A. Macheras;

e-mail: gmachera@otenet.gr

C2006 British Editorial

Society of Bone and

Joint Surgery

doi:10.1302/0301-620X.88B3.

$16940 \$ 2.00$

$J$ Bone Joint Surg $[B r]$

2006;88-B:304-9.

Received 6 July 2005;

Accepted after revision

25 October 2005

\title{
Radiological evaluation of the metal-bone interface of a porous tantalum monoblock acetabular component
}

\begin{abstract}
Between January 1998 and December 1998, 82 consecutive patients (86 hips) underwent total hip arthroplasty using a trabecular metal monoblock acetabular component. All patients had a clinical and radiological follow-up evaluation at six, 12 and 24 weeks, 12 months, and then annually thereafter. On the initial post-operative radiograph 25 hips had a gap between the outer surface of the component and the acetabular host bed which ranged from 1 to $5 \mathrm{~mm}$. All patients were followed up clinically and radiologically for a mean of 7.3 years ( 7 to 7.5 ). The 25 hips with the 1 to $5 \mathrm{~mm}$ gaps were studied for component migration at two years using the Einzel-Bild-Roentgen-Analyse (EBRA) digital measurement method. At 24 weeks all the post-operative gaps were filled with bone and no acetabular component had migrated. The radiographic outcome of all 86 components showed no radiolucent lines and no evidence of lysis. No acetabular implant was revised. There were no dislocations or other complications. The bridging of the interface gaps (up to $5 \mathrm{~mm}$ ) by the trabecular metal monoblock acetabular component indicates the strong osteoconductive, and possibly osteoinductive, properties of trabecular metal.
\end{abstract}

The survival of cementless acetabular components in total hip arthroplasty depends on many factors, including the design and manufacturing process, the stability of initial fixation, the surface texture and any osteoconductive and osteoinductive properties of the component. ${ }^{1-7}$

In the presence of fibrous tissue interposition at the metal-bone interface the junction is subjected to mechanical fatigue and to the biological effects of wear debris, which provoke peri-prosthetic osteolysis and loosening of the implant. ${ }^{6-9}$ Preventing the entry of wear debris into the interface between the component and bone may reduce osteolysis. In cementless components this can be achieved by improving bone ingrowth into the porous surface of the prosthesis.

Several alloys have been used for the production of cementless acetabular components, each with its own advantages and disadvantages. ${ }^{6,7}$ In 1997 porous tantalum was first used in orthopaedic surgery. It has unique biological and mechanical properties ${ }^{10-12}$ and was used to replace the titanium shell of an established non-modular acetabular design which contained a shrink-fitted polyethylene insert intended to eliminate micromotion and wear at the interface between the polyethylene and the porous-coated titanium shell. ${ }^{13}$ The trabecular metal modification had the polyethylene insert moulded directly into it. ${ }^{14}$ It was anticipated that these changes would increase osseointegration, with improved initial fixation owing to friction between implant and bone, and reduce peri-acetabular stress shielding by matching the elastic modulus of bone with that of porous tantalum. ${ }^{10,15-17}$

We undertook a radiological study to evaluate the osteoconductive, and possibly osteoinductive, properties of the trabecular metalbone interface and the possibility of bridging interface gaps of up to $5 \mathrm{~mm}$.

\section{Patients and Methods}

Between January 1998 and December 1998, 82 consecutive patients (86 hips) underwent total hip arthroplasty by a single surgeon (GAM). There were 59 women with a mean age at operation of 63 years (32 to 79 ) and 23 men with a mean age of 71 years (47 to 81). The underlying diagnosis was idiopathic osteoarthritis in 73 hips, avascular necrosis in six, congenital hip disease in three and posttraumatic arthritis in four. There were 41 right and 45 left hips.

The elliptical press-fit porous tantalum monoblock component (Trabecular Metal Monoblock Acetabular Cup System, Zimmer Inc., Warsaw, Indiana) and the cemented Con- 
tinuum Cast Hip Stem F-115 (Implex, Allendale, New Jersey) were implanted in all hips. In all cases a $28 \mathrm{~mm}$ ceramic femoral head was used.

The porous tantalum acetabular monoblock component ${ }^{12,13}$ used in this study is hemi-ellipsoid-shaped; the diameter of its equator is $2 \mathrm{~mm}$ larger than its polar diameter. It is inserted using a press-fit technique, taking particular care to prevent the interposition of soft tissue. The coefficient of friction of porous tantalum on bone is approximately twice that of other porous-surfaced biomaterials. The mean pore diameter of the porous tantalum shell is 550 $\mu \mathrm{m}$. The polyethylene liner is compression-moulded into the shell to a depth of 1 to $2 \mathrm{~mm}$, leaving 2 to $3 \mathrm{~mm}$ of porous tantalum for tissue ingrowth. ${ }^{14}$ This process allows a $48 \mathrm{~mm}$ acetabular component to incorporate a minimum total polyethylene thickness of $8.5 \mathrm{~mm}$ for a $28 \mathrm{~mm}$ femoral head, whereas a $40 \mathrm{~mm}$ acetabular component allows a minimum total polyethylene thickness of $8 \mathrm{~mm}$ for a 22 $\mathrm{mm}$ femoral head.

Trabecular metal has an unusually large and interconnecting porous surface which corresponds to between $75 \%$ and $80 \%$ of its total volume, and an overall geometry, shape and size similar to those of cancellous bone. ${ }^{10-13,18}$ The high-volume porosity enables extensive tissue infiltration and strong attachment. The microtexture of trabecular metal is osteoconductive. ${ }^{19}$ The metal elasticity of trabecular bone is $3 \mathrm{GPa}$, which is between those of cancellous ( 0.1 $\mathrm{GPa})$, subchondral (2 GPa), and cortical bone (15 GPa). Titanium alloys (110 GPa) and cobalt-chromium alloys $(220 \mathrm{GPa})$ are much less elastic.

A posterior approach was used in all cases. The acetabulum was prepared with hemispherical reamers. The diameter of the final reamer was the same as the polar diameter of the acetabular component and $2 \mathrm{~mm}$ less than the dimension of the equator. Bone grafts were not used in any case. At operation the initial stability of the acetabular component was assessed manually and was satisfactory in all cases. No supplementary peripheral screws were used.

Immediately after the operation all patients had an anteroposterior radiograph of the pelvis and anteroposterior and lateral radiographs of the operated hip.

Post-operative rehabilitation consisted of bed rest on post-operative day one, followed by partial weight-bearing with the use of crutches. Full weight-bearing with assistance (crutches) was allowed by the fourth post-operative week, and crutches were discontinued between the fifth and sixth post-operative weeks. The post-operative rehabilitation programme was the same for all patients.

All patients were evaluated clinically and radiologically at six, 12, and 24 weeks, 12 months, and annually thereafter, using the Harris hip score $\mathrm{e}^{20}$ and standard pelvic radiographs which were taken in the same department with the patient in a decubitus position and with a vertical beam centred on the pubic symphysis. The distance between the source and the plate was one metre.

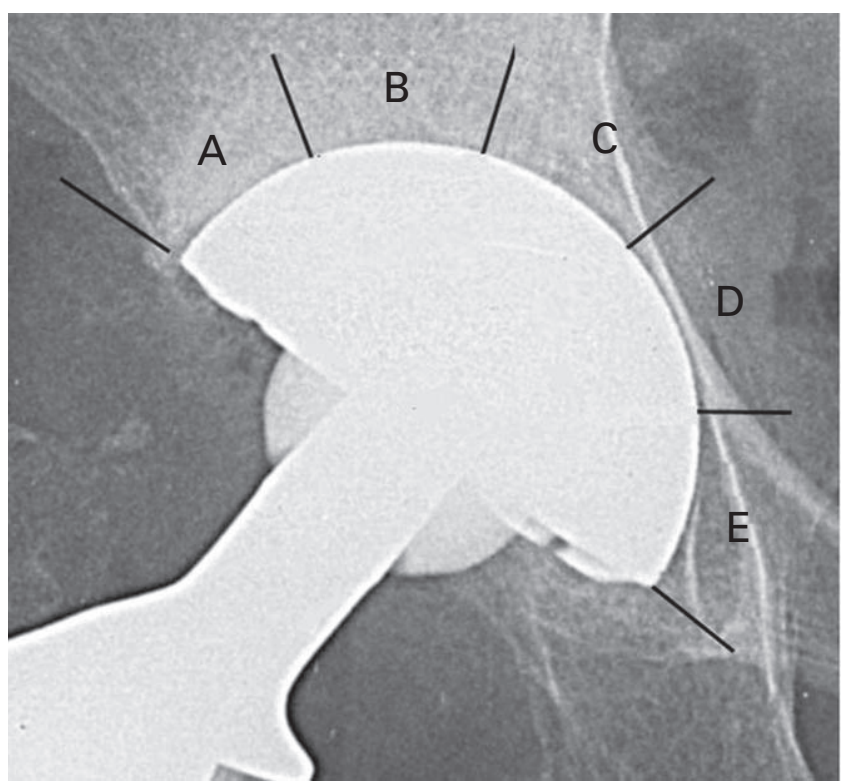

Fig. 1

Anteroposterior radiograph of the right hip showing the division of the acetabular bone into five zones.

In order to enable an accurate description of the topography of the acetabular component in relation to bone and the possible bone response, the acetabular bone was divided into five zones (A, B, C, D, and E) on the anteroposterior pelvic radiograph (Fig. 1). This process has been described in an experimental model by Bobyn et $\mathrm{al}^{11}$ and was chosen in preference to the traditional DeLee-Charnley three-zone division ${ }^{21}$ because it afforded greater detail and accuracy.

All radiographs were scanned digitally at a resolution of 150 dots per inch (dpi) and the data were processed and analysed using Adobe Photoshop 7.0 (Adobe Systems Inc., San Jose, California) to determine the zones and the width of the gaps.

The width of the gap in the five zones was corrected for magnification using the known diameter of the equator of the acetabular component. The gaps were measured by placing the cursor on the edge of the component and stretching a line to the bone edge. The corrected width of the gap, its location and changes with time were recorded.

Patients with gaps between the shell and the host bone on the initial radiograph had further analysis of their films for acetabular cup migration using the Einzel-Bild-Roentgen Analyse (EBRA) software (University of Innsburk, Austria) at the same time intervals. ${ }^{22,23}$ The EBRA-measurement system $^{22,24}$ is a method for measuring two-dimensional migration from digitised plain radiographs and has been used to predict acetabular component failure. ${ }^{25,26}$ The precision of this method has been shown to vary between 0.8 and $1 \mathrm{~mm}$ depending on the type and direction of motion analysed. ${ }^{27,28}$ Based on the measurement error of the EBRA 
Table I. Gap ( $\mathrm{mm}$ ) between bony acetabular floor and metallic shell according to the acetabular zone immediately post-operatively (time 0 ), and at six, 12,18 and 24 weeks

\begin{tabular}{|c|c|c|c|c|c|c|c|c|c|c|c|c|c|c|c|c|c|c|c|c|c|c|c|c|c|}
\hline & \multicolumn{5}{|c|}{ Zone A } & \multicolumn{5}{|c|}{ Zone B } & \multicolumn{5}{|c|}{ Zone C } & \multicolumn{5}{|c|}{ Zone D } & \multicolumn{5}{|c|}{ Zone E } \\
\hline & $\begin{array}{l}\text { Time } \\
\mathbf{0}\end{array}$ & 6 & 12 & 18 & 24 & 0 & 6 & 12 & 18 & 24 & 0 & 6 & 12 & 18 & 24 & 0 & 6 & 12 & 18 & 24 & 0 & 6 & 12 & 18 & 24 \\
\hline 1 & 0 & 0 & 0 & 0 & 0 & 0.9 & 0.5 & 0.2 & 0 & 0 & 2.5 & 1.8 & 0.9 & 0.4 & 0 & 0 & 0 & 0 & 0 & 0 & 0 & 0 & 0 & 0 & 0 \\
\hline 2 & 0 & 0 & 0 & 0 & 0 & 1.2 & 0.8 & 0.4 & 0 & 0 & 4.0 & 2.8 & 1.3 & 0.7 & 0 & 0 & 0 & 0 & 0 & 0 & 0 & 0 & 0 & 0 & 0 \\
\hline 3 & 0 & 0 & 0 & 0 & 0 & 0 & 0 & 0 & 0 & 0 & 1.0 & 0.7 & 0.3 & 0 & 0 & 0 & 0 & 0 & 0 & 0 & 0 & 0 & 0 & 0 & 0 \\
\hline 4 & 0 & 0 & 0 & 0 & 0 & 0 & 0 & 0 & 0 & 0 & 1.5 & 1.2 & 0.6 & 0 & 0 & 1.0 & 1.0 & 0.4 & 0 & 0 & 0 & 0 & 0 & 0 & 0 \\
\hline 5 & 0 & 0 & 0 & 0 & 0 & 1.5 & 0.8 & 0.4 & 0 & 0 & 4.0 & 2.8 & 1.2 & 0.6 & 0 & 1.5 & 1.2 & 0.5 & 0 & 0 & 0 & 0 & 0 & 0 & 0 \\
\hline 6 & 0 & 0 & 0 & 0 & 0 & 1.5 & 1.3 & 0.7 & 0.2 & 0 & 2.5 & 1.4 & 0.6 & 0 & 0 & 0 & 0 & 0 & 0 & 0 & 0 & 0 & 0 & 0 & 0 \\
\hline 7 & 0 & 0 & 0 & 0 & 0 & 0.8 & 0.5 & 0 & 0 & 0 & 2.0 & 1.6 & 0.9 & 0.3 & 0 & 1.0 & 1.0 & 0.6 & 0.2 & 0 & 0 & 0 & 0 & 0 & 0 \\
\hline 8 & 0 & 0 & 0 & 0 & 0 & 0.4 & 0.2 & 0 & 0 & 0 & 2.5 & 1.5 & 0.8 & 0.2 & 0 & 1.5 & 1.2 & 0.6 & 0.3 & 0 & 0 & 0 & 0 & 0 & 0 \\
\hline 9 & 0 & 0 & 0 & 0 & 0 & 0.9 & 0.5 & 0.3 & 0 & 0 & 4.0 & 2.8 & 1.6 & 0.8 & 0 & 1.0 & 1.0 & 0.5 & 0.2 & 0 & 0 & 0 & 0 & 0 & 0 \\
\hline 10 & 0 & 0 & 0 & 0 & 0 & 0.7 & 0.3 & 0 & 0 & 0 & 1.5 & 0.5 & 0.3 & 0 & 0 & 0 & 0 & 0 & 0 & 0 & 0 & 0 & 0 & 0 & 0 \\
\hline 11 & 0 & 0 & 0 & 0 & 0 & 0 & 0 & 0 & 0 & 0 & 1.0 & 1.0 & 0.4 & 0 & 0 & 0.5 & 0.2 & 0 & 0 & 0 & 0 & 0 & 0 & 0 & 0 \\
\hline 12 & 0 & 0 & 0 & 0 & 0 & 0.7 & 0.5 & 0 & 0 & 0 & 1.5 & 1.0 & 0.3 & 0 & 0 & 0.6 & 0.2 & 0 & 0 & 0 & 0 & 0 & 0 & 0 & 0 \\
\hline 13 & 0 & 0 & 0 & 0 & 0 & 1.3 & 1.0 & 0.6 & 0.2 & 0 & 2.5 & 2.0 & 1.1 & 0.4 & 0 & 0.7 & 0.6 & 0.2 & 0 & 0 & 0 & 0 & 0 & 0 & 0 \\
\hline 14 & 0 & 0 & 0 & 0 & 0 & 1.2 & 0.8 & 0.5 & 0.2 & 0 & 5.0 & 3.6 & 2.0 & 0.8 & 0 & 1.4 & 1.2 & 0.6 & 0.2 & 0 & 0 & 0 & 0 & 0 & 0 \\
\hline 15 & 0 & 0 & 0 & 0 & 0 & 0 & 0 & 0 & 0 & 0 & 1.5 & 1.1 & 0.6 & 0.2 & 0 & 0 & 0 & 0 & 0 & 0 & 0 & 0 & 0 & 0 & 0 \\
\hline 16 & 0 & 0 & 0 & 0 & 0 & 0.8 & 0.5 & 0.4 & 0.2 & 0 & 2.3 & 2.0 & 1.2 & 0.7 & 0 & 1.3 & 1.0 & 0.6 & 0 & 0 & 0 & 0 & 0 & 0 & 0 \\
\hline 17 & 0 & 0 & 0 & 0 & 0 & 0.8 & 0.8 & 0.4 & 0.2 & 0 & 4.0 & 3.0 & 1.9 & 0.8 & 0 & 1.2 & 0.9 & 0.6 & 0.2 & 0 & 0 & 0 & 0 & 0 & 0 \\
\hline 18 & 0 & 0 & 0 & 0 & 0 & 1.6 & 1.4 & 1.0 & 0.5 & 0 & 2.0 & 1.4 & 0.9 & 0.4 & 0 & 1.2 & 0.6 & 0.2 & 0 & 0 & 0 & 0 & 0 & 0 & 0 \\
\hline 19 & 0 & 0 & 0 & 0 & 0 & 1.0 & 0.8 & 0.6 & 0.2 & 0 & 1.4 & 1.0 & 0.7 & 0.4 & 0 & 0.6 & 0.4 & 0.2 & 0 & 0 & 0 & 0 & 0 & 0 & 0 \\
\hline 20 & 0 & 0 & 0 & 0 & 0 & 1.4 & 0.8 & 0.5 & 0.2 & 0 & 5.0 & 3.2 & 1.9 & 0.8 & 0 & 1.8 & 1.4 & 1.1 & 0.5 & 0 & 0 & 0 & 0 & 0 & 0 \\
\hline 21 & 0 & 0 & 0 & 0 & 0 & 0 & 0 & 0 & 0 & 0 & 1.3 & 1.1 & 0.9 & 0.4 & 0 & 1.0 & 0.8 & 0.5 & 0.2 & 0 & 0 & 0 & 0 & 0 & 0 \\
\hline 22 & 0 & 0 & 0 & 0 & 0 & 1 & 0.6 & 0.2 & 0 & 0 & 2.2 & 1.8 & 1.2 & 0.5 & 0 & 0.6 & 0.5 & 0.3 & 0 & 0 & 0 & 0 & 0 & 0 & 0 \\
\hline 23 & 0 & 0 & 0 & 0 & 0 & 0.8 & 0.2 & 0.2 & 0 & 0 & 2.5 & 1.6 & 0.8 & 0.3 & 0 & 1.8 & 1.4 & 1.0 & 0.4 & 0 & 0 & 0 & 0 & 0 & 0 \\
\hline 24 & 0 & 0 & 0 & 0 & 0 & 1.4 & 0.9 & 0.5 & 0.2 & 0 & 2.9 & 1.8 & 1.1 & 0.6 & 0 & 1.2 & 0.7 & 0.2 & 0 & 0 & 0 & 0 & 0 & 0 & 0 \\
\hline 25 & 0 & 0 & 0 & 0 & 0 & 1.5 & 1.0 & 0.6 & 0.2 & 0 & 3.2 & 2.4 & 1.6 & 0.9 & 0 & 1.8 & 1.3 & 0.6 & 0.2 & 0 & 0 & 0 & 0 & 0 & 0 \\
\hline
\end{tabular}

software, migration values less than $1 \mathrm{~mm}$ are not considered significant. $^{22,27,28}$

\section{Results}

The mean follow-up of all 86 hips was 7.3 years (7 to 7.5 ). None of the patients was lost to follow-up.

In the immediate post-operative radiograph, full contact between the acetabular bone and the implant was observed in 54 patients ( 56 hips). In five patients (five hips) a 0.2 to $0.4 \mathrm{~mm}$ gap was found in zone $\mathrm{C}$ owing to incomplete reaming at the bottom of the acetabular bone bed, leading to a small gap at the area of the acetabular fossa.

In 25 patients ( 25 hips), a gap between implant and bone ranging from 1 to $5 \mathrm{~mm}$ was identified (Figs $2 \mathrm{a}$ and 3a). Table I shows the gap distribution for all 25 hips. Most gaps were in zone $\mathrm{C}$, followed by zone B and then zone $\mathrm{D}$. We found more gaps in transition zone $\mathrm{BC}$ than in zone $\mathrm{CD}$. The gaps were obliterated more quickly in zone $\mathrm{B}$ and in transition $\mathrm{CD}$ than in zone $\mathrm{D}$ and transition zone BC. All these 25 acetabular components were implanted during the first quarter of 1998 , while the surgical team was gaining experience with this new implant and technique.

By 24 weeks all gaps had closed radiologically (Figs $2 \mathrm{~b}$ and c, $3 b$ and c). Using the EBRA method, the 25 hips with gaps present were analysed and component migration was calculated for a two-year period. Data were obtained for migration along the horizontal and vertical axes. EBRA's algorithm for comparability rejected one radiograph for evaluation on the horizontal axis and three radiographs for evaluation on the vertical axis. The total migration was computed for each acetabular component at each followup visit using Pythagoras' theorem on the horizontal and vertical dimensions. ${ }^{25}$ The mean absolute horizontal postoperative migration (X axis) was $0.24 \mathrm{~mm}$ (SEM 0.17 to 0.32 ). The mean absolute vertical migration ( $\mathrm{Y}$ axis) was $0.29 \mathrm{~mm}$ (SEM 0.20 to 0.38 ). The mean total component migration was $0.41 \mathrm{~mm}$ (SEM 0.33 to 0.52 ).

In the group of 57 patients (61 hips) without a gap, the mean pre-operative Harris hip score improved from 52 (17 to 66 ) to 94 (76 to 100 ). In the 25 patients ( 25 hips) with acetabular interface gaps, the mean pre-operative Harris hip score improved from 50 (15 to 65) to 93 (75 to 100). There were no dislocations or implant-related complications. All patients regained their previous activities. At the last follow-up examination no radiolucent lines and no areas of osteolysis were observed in any of the 86 hips. No acetabular implant had been revised.

\section{Discussion}

Common materials used to manufacture acetabular component shells are various titanium and cobalt-chromium alloys. The external surface of the shell is processed by various techniques, such as sintered beads, plasma spray, metal fibres etc., to create a porous surface on to which bone will grow to achieve biological fixation. ${ }^{19,23,29-31}$ The total porous surface of all these materials corresponds to between $30 \%$ and $50 \%$ of their volume, which limits over- 


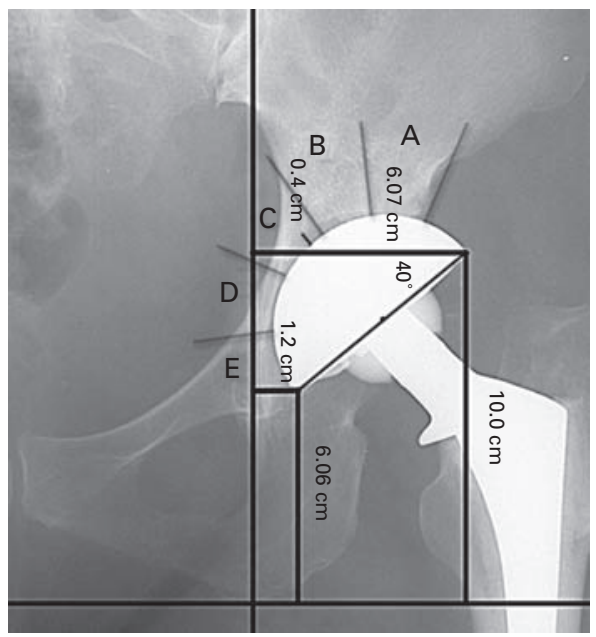

Fig. 2a



Fig. $2 b$

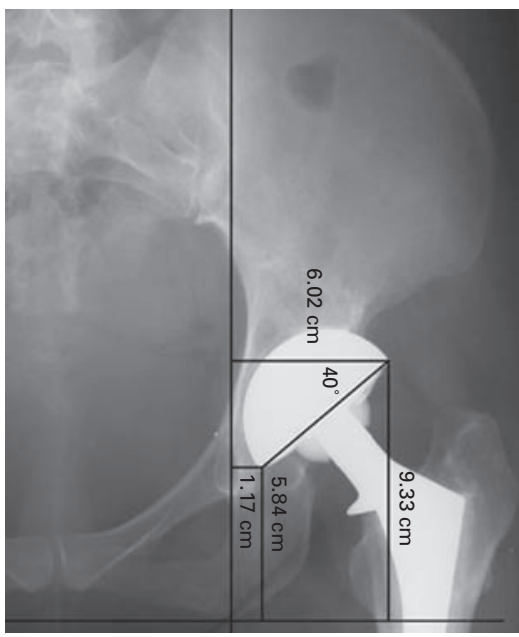

Fig. 2c

Figure $2 \mathrm{a}$ - Anteroposterior radiograph of the left hip immediately post-operatively showing a porous tantalum acetabular component. There is a $4 \mathrm{~mm}$ gap between the metal shell and the floor of the acetabulum. Figure $2 \mathrm{~b}$ - At 12 weeks there was a $0.6 \mathrm{~mm}$ gap between the metal shell and the floor of the acetabulum. Figure 2c - At 24 weeks, no gap was observed.

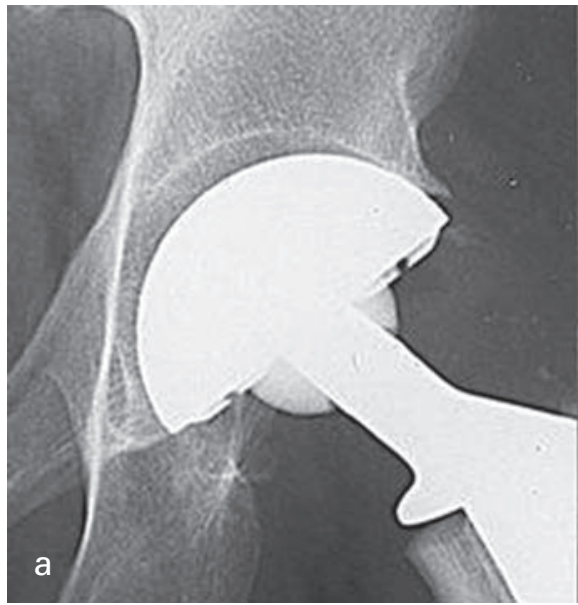

b

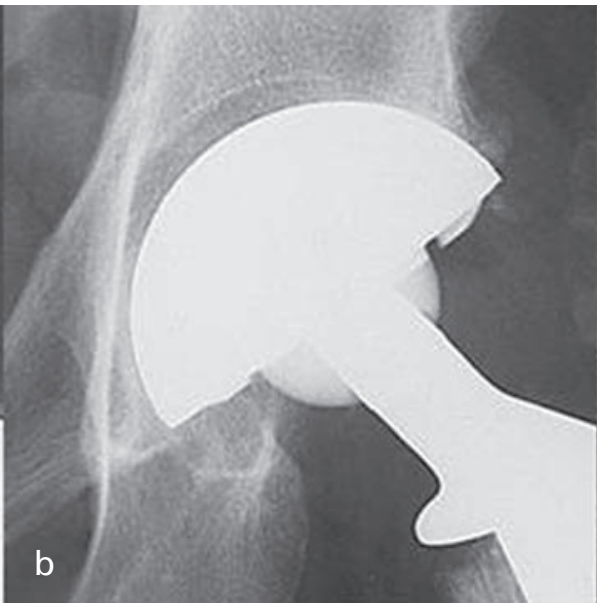

Fig. 3

Figure 3a - Anteroposterior radiograph of the left hip immediately post-operatively shows a porous tantalum acetabular componenet with a gap between the metal shell and the floor of the acetabulum. Figure $3 b-$ Radiograph at six weeks. Figure $3 c-A t 24$ weeks no gap was observed between the metal shell and the floor of the acetabulum.

all bone tissue ingrowth and hence biological fixation. In retrieval studies of acetabular components, the mean area over which bone ingrowth was found did not exceed $30 \%$ of the total surface area of the component. . $^{32,33}$

Acetabular components have been associated with the production of metallic and polyethylene debris both from the bearing surface of the polyethylene liner, as well as from the back of polyethylene liner and the interior surface of the metallic shell. ${ }^{13,34}$ This particulate debris can migrate to the shell-bone interface through areas of minor resistance and has been implicated in osteolysis and loosening of the com- ponent. ${ }^{8,13,34}$ It is, therefore, imperative to reduce the production and the migration of such debris.

Owing to the direct fusion and compression of the polyethylene into the metal shell, the trabecular metal monoblock component used in this study has the advantage of eliminating the interface between the shell and the liner as a source of wear debris. It also enables bone ingrowth across a void and into the porous surface of the acetabular component. The characteristics of the porous surface, such as lower elastic modulus, higher porous interconnectivity, larger pore spaces, and perhaps improved surface bioactiv- 
ity, enhance bone ingrowth across a defect adjacent to the porous implant. ${ }^{35}$

Because of the high co-efficient of friction of the trabecular metal against bone, the initial fixation of the acetabular component is increased. ${ }^{36}$ However, as an inherent consequence of the peripheral rim press-fit, partial contact between the implant and the full surface of the acetabular bone bed is a frequent finding, with bone gaps, particularly at the apex of the acetabulum seen on the immediate postoperative radiographs. ${ }^{13,37}$ Other potential causes for this finding include the uneven and rough external surface of the shell, which adheres strongly to soft tissue and might impede impaction, and the fact that the polyethylene liner and the shell are a single piece obscuring visualisation of the dome contact.

In our series there was a higher incidence of initial postoperative gaps $(29 \%)$ compared with other studies using acetabular components of a similar design. Most of these gaps occurred in our early experience with this implant. However, their extent and location were similar to those described previously. ${ }^{38-43}$

Schmalzried and Harris, ${ }^{41}$ in a study using a first-generation press-fit component, attributed their radiographic observations to technique, with the prevalence of gaps in DeLee and Charnley zones I and III being a natural result of line-to-line fit and ancillary fixation in order to secure and bottom-out the component in zone II. MacKenzie et $\mathrm{al}^{42}$ in a laboratory study using cadavers, found gaps to be less than $1 \mathrm{~mm}$ with line-to-line fit, whereas 1.4 and $3.9 \mathrm{~mm}$ polar gaps were found for 2 and $4 \mathrm{~mm}$ press-fit components.

Onsten ${ }^{44}$ reported only two cases with gaps of 4 to $5 \mathrm{~mm}$ on the post-operative radiographs. However, he used unimpacted grafts to fill the gaps and the filling process took much longer (30 to 40 months). Gruen et al, ${ }^{37}$ in a multicentre study, reported post-operative acetabular gaps in 80 $(19 \%)$ of 414 hips using the same acetabular component, mainly in zone II. According to the authors the presence of zone II gaps resulted from the peripheral rim press-fit. The reported gaps of 4 to $5 \mathrm{~mm}$ closed within two years. There was no progression of any post-operative gap, no evidence of continuous peri-acetabular interface radiolucencies, no evidence of lysis and no revisions for loosening. In the same series, porous tantalum components were compared with porous-coated titanium components in a prospective randomised study. The radiographic outcomes showed a significantly larger number of initial gaps which filled completely for the porous tantalum monoblock component (five of five), compared with the low frequency of gap resolution observed for the porous-coated titanium component (three of 15). However, computer-assisted determination of magnification and patient positioning on serial radiographs was not performed, thus creating a large potential source of error in the serial measurement of gap filling.

To our knowledge, healing of gaps up to $5 \mathrm{~mm}$ in width at the bottom of an acetabular component within six months of the operation has not previously been described. We accept that the apparent gaps may have disappeared by 24 weeks, owing to loss of the denser line in the unloaded void behind the component, as much as to bone filling the void. $^{32,45}$ Only a CT scan would determine whether the void has filled with bone. ${ }^{46}$

Nevertheless, in our study, EBRA examination of the acetabular components with gaps revealed no significant component migration. This implies that the disappearance of gaps could not be the result of component migration into the void. We believe that these observations indicate the strong osteoconductive (and possibly osteoinductive) properties of the porous tantalum. These properties, shown in the laboratory study by Findlay et $a 1,{ }^{47}$ seem to have clinical significance in promoting the filling of gaps between implant and bone.

Another benefit of this material is the more normal physiological transfer of load to host bone. A finite element analysis ${ }^{48}$ demonstrated that the porous tantalum monoblock component loaded the acetabular bone similarly to a cemented all-polyethylene component, with load effectively transferred to the superomedial portion of the acetabulum as occurs physiologically. In the same study, finite element analysis of a titanium-backed acetabular component revealed stress shielding of the superomedial portion of the acetabulum. These findings were attributed to the bonematched elastic modulus of the porous tantalum ( $3 \mathrm{GPa})$, compared with titanium alloy (110 GPa).

In conclusion, the use of porous tantalum appears to provide a solution to issues which affect primary acetabular fixation, premature migration and possibly backside polyethylene wear and subsequent osteolysis. Further clinical and radiographic assessment of the behaviour of these prostheses will confirm the accuracy of these early observations.

No benefits in any form have been received or will be received from a commercial party related directly or indirectly to the subject of this article.

\section{References}

1. Cameron HU, Pilliar RM, Macnab I. The rate of bone ingrowth into porous metal. J Biomed Mater Res 1976;10:295-302.

2. Bobyn JD, Pilliar RM, Cameron HU, Weatherly GC. The optimum pore size for the fixation of porous-surfaced metal implants by the ingrowth of bone. Clin Orthop 1980;150:263-70

3. Bobyn JD, Pilliar RM, Cameron HU, Weatherly GC. Osteogenic phenomena across endosteal bone-implant spaces with porous-surfaced intramedullary implants. Acta Orthop Scand 1981;52:145-53.

4. Bobyn JD, Engh CA. Human histology of the bone-porous metal implant interface. Orthopedics 1984;7:1410-21.

5. Engh CA, Gloss FE, Bobyn JD. Biologic fixation arthroplasty in the treatment of osteonecrosis. Orthop Clin North Am 1985;16:771-87.

6. Friedman RJ, Black J, Galante JO, Jacobs JJ, Skinner HB. Current concepts in orthopaedic biomaterials and implant fixation. Instr Course Lect 1994;43:233-55.

7. Bobyn JD, Tanzer M, Miller JE. Fundamental principles of biologic fixation. In: Morrey BF, ed. Reconstructive surgery of the joints. New York: Churchill Livingstone, 1996:75-94.

8. Schmalzried TP, Jasty M, Harris WH. Periprosthetic bone loss in total hip arthroplasty: polyethylene wear debris and the concept of the effective joint space. J Bone Joint Surg [Am] 1992;74-A:849-63.

9. Bobyn JD, Jacobs JJ, Tanzer M, et al. The susceptibility of smooth implant surfaces to periimplant fibrosis and migration of polyethylene wear debris. Clin Orthop 1995;311:21-39. 
10. Bobyn JD, Stackpool G, Hacking SA, Tanzer M, Krygier JJ. Characteristics of bone ingrowth and interface mechanics of a new porous tantalum biomaterial. J Bone Joint Surg [Br] 1999;81-B:907-14.

11. Bobyn JD, Toh KK, Hacking SA, Tanzer M, Krygier JJ. Tissue response to porous tantalum acetabular cups: a canine model. J Arthroplasty 1999;14:347-54.

12. Macheras G, Tsiamtsouris K, Kostakos A, Poulis N. Clinical and radiological behavior of tantalum acetabular component. Hip Int 2001;11(S1):188.

13. Sculco TP. The acetabular component: an elliptical monoblock alternative. J Arthroplasty 2002;17(Suppl 1):118-20.

14. Poggie RA, Cohen RC, Averill RG. Characterization of a porous metal, direct compression moulded UHMWPE junction. Trans Orthop Res Soc 1998;23:777.

15. Stiehl JB, Poggie RA. Improved wear resistance of direct compression molded and cross-linked polyethylene. Procs 68th Annual Meeting American Academy of Orthopaedic Surgeons, 2001.

16. Bobyn JD, Hacking SA, Krygier JJ, et al. Characterization of a new porous tantalum biomaterial for reconstructive surgery. Procs 66th Annual Meeting American Academy of Orthopaedic Surgeons, 1999.

17. Bobyn JD, Poggie RA, Krygier JJ, et al. Clinical validation of a structural porous tantalum biomaterial for adult reconstruction. J Bone Joint Surg [Am] 2004;86-A (Suppl 2):123-9.

18. Toh K-K, Chan SP, Bobyn JD, et al. Bone growth into a porous tantalum biomaterial with calcium phosphate coating. In: SIROT 99 (Stein H, Suk S-I, Leung P-C, Thorngren K-G, Akeson W, eds). London: Freund Publishing House Ltd, 1999:354-8.

19. Kieswetter K, Schwartz Z, Hummert TW, et al. Surface roughness modulates the local production of growth factors and cytokines by osteoblast-like MG-63 cells. J Biomed Mater Res 1996;32:55-63.

20. Harris WH. Traumatic arthritis of the hip after dislocation and acetabular fracture: treatment with mold arthroplasty. J Bone Joint Surg [Am]1969;51-A:737-55.

21. DeLee JG, Charnley J. Radiographic demarcation of cemented sockets in total hip replacement. Clin Orthop 1976;121:20-32.

22. Krismer M, Bauer R, Tschupik JP, Mayrhofer P. EBRA: a method to measure migration of acetabular components technical note. J Biomechanics 1995;28: 1225-36.

23. Spector M. Bone ingrowth into porous metals. In: Williams DF, ed. Biocompatibility of orthopaedic implants. Vol 2. Boca Raton: CRC Press Inc., 1982:89-128.

24. Tschupik JP. Grundlagen und straegien des problemspezifishen roentgenbildmessverfahrens EBRA (Einbildroentgenanalyse). In: Russe W, ed. Roentgenphotogrammetrie der kunstichen huft gelenkspfanne. Bern: Huber, 1988:16-41.

25. Krismer M, StockI B, Fischer M, et al. Early migration predicts late aseptic failure of hip sockets. J Bone Joint Surg [Br] 1996;78-B:422-6.

26. Hendrich C, BahImann J, Eulert J. Migration of the uncemented Harris-Galante acetabular cup: results of the einbildroentgenanalyse (EBRA) method. J Arthroplasty 1997:12:889-95

27. Phillips NJ, Stockley I, Wilkinson JM. Direct plain radiographic methods versus EBRA-digital for measuring implant migration after total hip arthroplasty. J Arthroplasty 2002;17:917-25

28. Wilkinson JM, Hamer AJ, Elson RA, Stockley I, Eastell R. Precision of EBRAdigital software for monitoring implant migration after total hip arthroplasty. J Arthroplasty 2002:17:910-16.
29. Schmalzried TP, Wessinger SI, Hill GE, Harris WH. The Harris-Galante porous acetabular component press-fit without screw fixation: five-year radiographic analysis of primary cases. J Arthroplasty 1994;8:235-42.

30. Goldberg VM, Stevenson S, Feighan J, Davy D. Biology of grit-blasted titanium alloy implants. Clin Orthop 1995;319:122-9.

31. Wright J, Bostrom M, Pellici P, Salvati E. Depth of insertion and radiographic fate of non-holed cementless metal hacked acetabular components. Hip Int 2000;10:161-5.

32. Cook SD, Barrack RL, Thomas KA, Haddad RJ Jr. Quantitative analysis of tissue growth into human porous total hip components. J Arthroplasty 1988;3:249-62.

33. Collier JP, Bauer TW, Bloebaum RD, et al. Results of implant retrieval from postmortem specimens in patients with well-functioning long-term total hip replacement Clin Orthop 1992:274:97-112.

34. Huk $\mathbf{0}$, Bansal $\mathbf{M}$, Betts $\mathbf{F}$, et al. Polyethylene and metal debris generated by nonarticulating surfaces of modular acetabular components. J Bone Joint Surg [Br] 1994; 76-B:568-74.

35. Bragdon CR, Doherty AM, Chiang PP, et al. The effect of trabecular metal porous surface on gap healing and bone ingrowth fixation in a canine total hip model. Trans Orthop Res Soc 2004;29:257.

36. Zhang Y, Ahn PB, Fitzpatrick DC, et al. Interfacial frictional behavior: cancellous bone, cortical bone, and a novel porous tantalum biomaterial. J Musculoskeletal Res 1999;3:245-7.

37. Gruen TA, Poggie RA, Lewallen DG, et al. Radiographic evaluation of a monoblock acetabular component. J Arthroplasty 2005;20:369-78.

38. Dorr LD, Wan Z, Cohen J. Hemispheric titanium porous coated acetabular component without screw fixation. Clin Orthop 1998;351:158-68.

39. Incavo SJ, DiFazio FA, Howe JG. Cementless hemispheric acetabular components: 2-4-year results. J Arthroplasty 1993;8:573-80.

40. Incavo SJ, Ames SE, DiFazio FA, Howe JG. Cementless hemispheric acetabular components: a 4- to 8-year follow-up report. J Arthroplasty 1996;11:298-303.

41. Schmalzried TP, Harris WH. The Harris-Galante porous-coated acetabular component with screw fixation: radiographic analysis of eighty-three primary hip replacements at a minimum of five years. J Bone Joint Surg [Am] 1992;74-A:1130-9.

42. MacKenzie JR, Callaghan JJ, Pedersen DR, Brown TD. Areas of contact and extent of gaps with implantation of oversized acetabular components in total hip arthroplasty. Clin Orthop 1994;298:127-36.

43. Thanner J, Karrholm J, Herberts P, Malchau H. Porous cups with and without hydroxyapatite-tricalcium phosphate coating. J Arthroplasty 1999;14:266-71.

44. Onsten I. Appositional bone bridging of primary gaps in the dome area uncemented, porous acetabular components. J Arthroplasty 1995;10:702-6.

45. Engh CA, ZettI-Schaffer KF, Kukita Y, et al. Histological and radiographic assessment of well functioning porous-coated acetabular components: a human postmortem retrieval study. J Bone Joint Surg [Am] 1993;75-A:814-24.

46. Howard JL, Hui AJ, Bourne RB, Holdsworth DW. Computed tomographic analysis of bone support for three acetabular cup designs. Clin Orthop 2005;434:163-9.

47. Findlay DM, Welldon K, Atkins GJ, et al. The proliferation and phenotypic expression of human osteoblasts on tantalum metal. Biomaterials 2004;25:2215-27.

48. Poggie RA, Brown TD, Pedersen DR. Finite element analysis of peri-acetabular stress of cemented, metal-backed, and porous tantalum backed acetabular components. Trans Orthop Res Soc 1999;24:747. 